\title{
Diffusion Tensor Imaging of White Matter in Children Born from Preeclamptic Gestations
}

\author{
(D) E.A. Figueiró-Filho, (DB.A. Croy, (D).N. Reynolds, (D)F. Dang, (DD. Piro, (D) M.T. Rätsep, DN.D. Forkert, (D)A. Paolozza, (D) G.N. Smith, \\ and 1 P.W. Stroman

\begin{abstract}
BACKGROUND AND PURPOSE: Individuals born from pregnancies complicated by preeclampsia have an elevated risk for cognitive impairment. Deviations in maternal plasma angiokines occur for prolonged intervals before clinical signs of preeclampsia. We hypothesized that fetal brain vascular and nervous tissue development become deviated during maternal progression toward preeclampsia and that such deviations would be detectable by MR imaging.
\end{abstract}

MATERIALS AND METHODS: In this pilot study, 10 matched (gestational and current ages) pairs (5 boys/5 girls, 7-10 years of age) from preeclampsia or control pregnancies were examined by using diffusion tensor MR imaging. An unbiased voxel-based analysis was conducted on fractional anisotropy and mean diffusivity parametric maps. Six brain ROls were identified for subsequent analysis by tractography (middle occipital gyrus, caudate nucleus and precuneus, cerebellum, superior longitudinal fasciculus, and cingulate gyrus).

RESULTS: Statistical differences were present between groups for fractional anisotropy in the caudate nucleus (offspring from preeclamptic gestation > controls), volume of the tract for the superior longitudinal fasciculus (offspring from preeclamptic gestation $>$ controls) and the caudate nucleus (offspring from preeclamptic gestation $>$ controls), and for parallel diffusivity of the cingulate gyrus (offspring from preeclamptic gestation $>$ controls)

CONCLUSIONS: These novel preliminary results along with previous results from the same children that identified altered cerebral vessel calibers and increased regional brain volumes justify fully powered MR imaging studies to address the impact of preeclampsia on human fetal brain development.

ABBREVIATIONS: $F A=$ fractional anisotropy; $M D=$ mean diffusivity; $P E=$ preeclampsia; $P E-F$ = offspring from preeclamptic gestation; $P G F=$ placental growth factor

$\mathrm{H}^{2}$

ypertensive disorders during human pregnancy include acute-onset emergency preeclampsia (PE), seen at a frequency of $2 \%-8 \%$ of all gestations. ${ }^{1} \mathrm{PE}$ is a systemic vascular inflammatory syndrome occurring between midpregnancy and term and is the leading cause of maternal and fetal morbidity and mortality. Up to $12 \%$ of annual maternal deaths ${ }^{2}$ and up to $25 \%$ of annual fetal and neonatal deaths globally ${ }^{3}$ are PE-associated.

Received July 6, 2016; accepted after revision November 6

From the Departments of Biomedical and Molecular Sciences (E.A.F.-F., B.A.C. J.N.R., F.D., D.P., N.D.F., G.N.S.) and Obstetrics and Gynecology (M.T.R., G.N.S.), and Centre for Neuroscience Studies (E.A.F.-F., J.N.R., P.W.S.), Queen's University, Kings ton, Ontario, Canada; Faculty of Medicine (E.A.F.-F.), Federal University of Mato Grosso do Sul, Campo Grande, Mato Grosso do Sul, Brazil; Department of Radiology and Hotchkiss Brain Institute (N.D.F.), University of Calgary, Calgary, Alberta, Canada; and Laboratory for Infant Studies (A.P.), University of Toronto Scarborough, Scarborough, Ontario, Canada.

This work was supported by the Harry Botterell Foundation for the Neurological Sciences award and the Garfield Kelly Cardiovascular Research Development Fund from Kingston General Hospital Foundation, the Canada Research Chairs Program (P.W.S., B.A.C.), and a Postdoctoral Training Award-Estágio Sênior, grant No. 99999.002771/2015-02 from Coordenação de Aperfeiçoamento de Pessoal de Nível Superior, Brazil (E.A.F.-F.).
Leading hypotheses addressing the pathophysiology of PE focus on progressive deficits in uteroplacental angiogenesis and maternal vascular remodeling well before the onset of clinical signs, due to an imbalance in angiokines and soluble angiokine receptors, which are predominantly products of the placenta. ${ }^{4}$

A recent systematic review of the impact of maternal hypertension (all forms) during pregnancy on offspring addressed outcomes after 6 months of life. The review identified cardiovascular, immune, metabolic, and behavioral/neurologic effects on individuals born from preeclamptic mothers (PE-F1s). For PE-F1s, lower cognitive function was the prominent, reliable association. ${ }^{5}$

Please address correspondence to Ernesto Antonio Figueiró-Filho, MD, Department of Biomedical and Molecular Sciences, Queen's University, 18 Stuart St, Botterell Hall, 5th floor, Room 563, Kingston, ON, Canada; e-mail: eaff@queensu.ca

- Indicates open access to non-subscribers at www.ajnr.org

三 Indicates article with supplemental on-line table.

http://dx.doi.org/10.3174/ajnr.A5064 
The deficits in cognitive functions reported for $\mathrm{PE}-\mathrm{F} 1 \mathrm{~s}^{5-7}$ include lower intelligence quotient scores, ${ }^{8,9}$ reduced verbal and nonverbal abilities, ${ }^{10,11}$ and reduced arithmetic reasoning. ${ }^{12,13}$

Recently, we conducted a pilot study to determine whether clinical cognitive function test outcomes and brain MR imaging findings differed between PE-F1s and typical 7- to 10-year-old children. ${ }^{14}$ The hypothesis driving this research posits that the progressive dysregulation of angiokines that is clinically associated with maternal PE development reflects conditions occurring not only in placental but also in all fetal tissues and impacts fetal cerebrovascular development. This hypothesis ${ }^{15}$ predicts that brain anatomy and function differ between PE-F1s and children born from normotensive mothers due to the use of common molecular pathways during vascular and neuronal cell differentiation (vascular endothelial growth factor pathways) and to the importance of cerebral blood flow for anatomic and functional brain development. Our pilot study suggested specific deficits in cognitive testing and in eye-movement control. ${ }^{16}$ Initial volumetric analyses of brain anatomic regions by using high-resolution T1weighted MR imaging datasets identified 5 regions of anatomic enlargement in PE-F1s (cerebellum, temporal lobe, left amygdala, right amygdala, and brain stem). In addition, reduced vascular radii were identified from time-of-flight MR angiography datasets in the occipital and parietal lobes. ${ }^{14}$ These preliminary results were the first reported MR imaging/MRA findings in PE-F1s of any age group.

The aim of the current study was to determine whether microstructural properties, including myelination patterns and white matter connectivity analyzed by diffusion tensor MR imaging, differ between PE-F1s and matched typical children. A further goal was to assess whether DTI findings overlapped the previously identified anatomic or vascular deviations in these children. ${ }^{14}$

\section{MATERIALS AND METHODS Participants}

Twenty white children were recruited between July 2014 and February 2015 from the established Preeclampsia New Emerging Team birth cohort developed at Kingston General Hospital between September 2003 and October 2009. ${ }^{17}$ Race was not a condition for recruitment. Half of the children had experienced a PE gestation, while typical controls, matched for sex (5 males/5 females), gestational age, and current age, had experienced a normal pregnancy. PE was clinically defined by using the 2002 criteria of American College of Obstetricians and Gynecologists. ${ }^{17}$ All births were singleton and not complicated by diabetes and preexisting cardiovascular or other diseases. Lower weight was the sole difference between the participant groups. ${ }^{14,16}$ During a single half-day of study, each participant undertook multiple cognitive function tests and eye-movement control testing to analyze regional brain function, plus MR imaging and angiography protocols, including DTI, that did not require sedation or contrast medium enhancement. ${ }^{14}$ These participants have been fully described previously. ${ }^{14,16}$ Here, analyses of the DTI data collection are reported. The study was reviewed and approved by the Human Research Ethics Board, Queen's University and Kingston General Hospital.

\section{MR Imaging/DTI}

Brain MR imaging was performed by using a 3T Magnetom Trio MR imaging scanner (Siemens, Erlangen, Germany) as reported previously. ${ }^{14}$ DTI used in this work was a single-shot balanced echo-planar imaging sequence with timing parameters of $\mathrm{TR}=$ $6000 \mathrm{~ms}$ and $\mathrm{TE}=94 \mathrm{~ms}$ and flip angle $=90^{\circ}$. Fifty contiguous transverse sections with a section thickness of $2.2 \mathrm{~mm}$ were aligned parallel to the anterior/posterior commissure plane and covered the entire brain. The FOV was $211 \times 211 \mathrm{~mm}$, and the acquisition matrix was $96 \times 96$, giving a reconstructed in-plane resolution of $2.2 \times 2.2 \mathrm{~mm}$. For each section, 1 image without diffusion gradients $\left(b=0 \mathrm{~s} / \mathrm{mm}^{2}\right)$ and 30 images with diffusion gradients $\left(b=1000 \mathrm{~s} / \mathrm{mm}^{2}\right)$ applied along 30 noncollinear directions were acquired.

\section{Voxel-Based Analysis, ROIs, and Tractography}

DTI data were analyzed by using custom software developed in Matlab (R2009b; MathWorks, Natick, Massachusetts) and ExploreDTI (http://exploredti.com/). ${ }^{18}$ A 3-step analytic protocol was developed because no previous workflow has been reported for DTI analysis of juvenile PE-F1s, to our knowledge.

In the first step, to compensate for any potential motion artifacts, we registered the 30 DTI acquisitions for each subject to the first $b=0 \mathrm{~s} / \mathrm{mm}^{2}$ dataset by using an affine transformation by maximization of the mutual information cost function and linear interpolation. After motion correction, parametric maps of fractional anisotropy (FA) and mean diffusivity (MD) were calculated. To enable voxelwise statistical analysis, we transformed the FA and MD parametric maps for each subject nonlinearly to a common reference space by registering the $b=0 \mathrm{~s} / \mathrm{mm}^{2}$ dataset. For this purpose, a custom brain atlas was created on the basis of the anatomic images from all 20 children enrolled in this study by using the Individual Brain Atlases Using Statistical Parametric Mapping Software (http://thomaskoenig.ch/Lester/ibaspm.htm) atlas-based automatic segmentation toolbox ${ }^{19}$ to account for the pediatric population.

In the second step, voxel-based analysis was performed to compare white matter measurements between PE-F1s and control children. Voxelwise statistical comparisons of FA and MD parameters between the $10 \mathrm{PE}-\mathrm{F} 1 \mathrm{~s}$ and 10 typical children were performed by using Matlab and analysis of variance. Differences were considered statistically significant at $P \leq .01$ (Fig 1). From the voxel-based analysis, 6 ROIs were identified and used as seeds for subsequent tractography analysis by using ExploreDTI ${ }^{18}$ with standard parameters. More precisely, the 3 largest connected regions of significant voxels visible in at least 3 adjacent sections, determined by voxel-based analysis, were selected for each parameter (FA or MD) and used for further analysis after backpropagation to the original DTI space.

In the third step, tracts identified in ExploreDTI ${ }^{18}$ were used to calculate average FA, MD, parallel diffusivity, perpendicular diffusivity, and tract volume (averaging across all voxels in a given tract). The results between PE-F1s and typical children were compared in Matlab by using 1-way analysis of covariance, with age as a covariate. At this third step, differences in tractography were considered significant at $P \leq .05$.

At a significance level of $P \leq .05$, voxel-based analysis isolated 


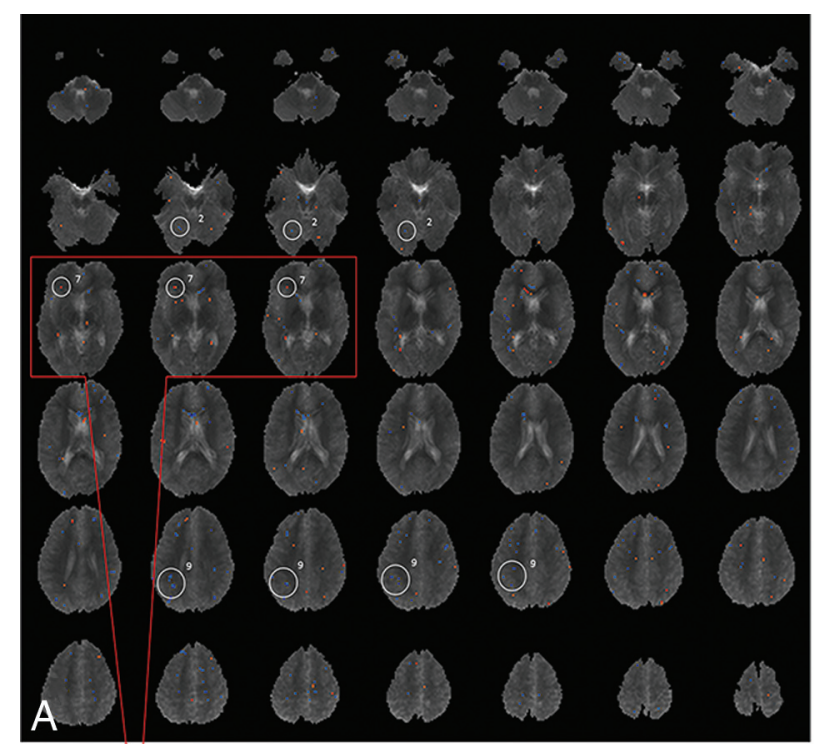

Fractional Anisotropy (FA) Mapping

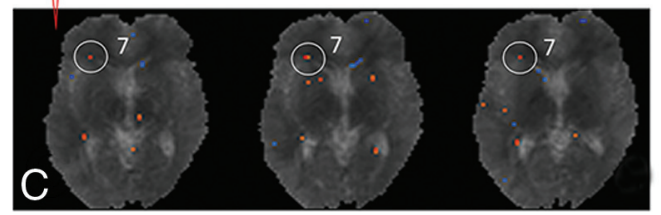

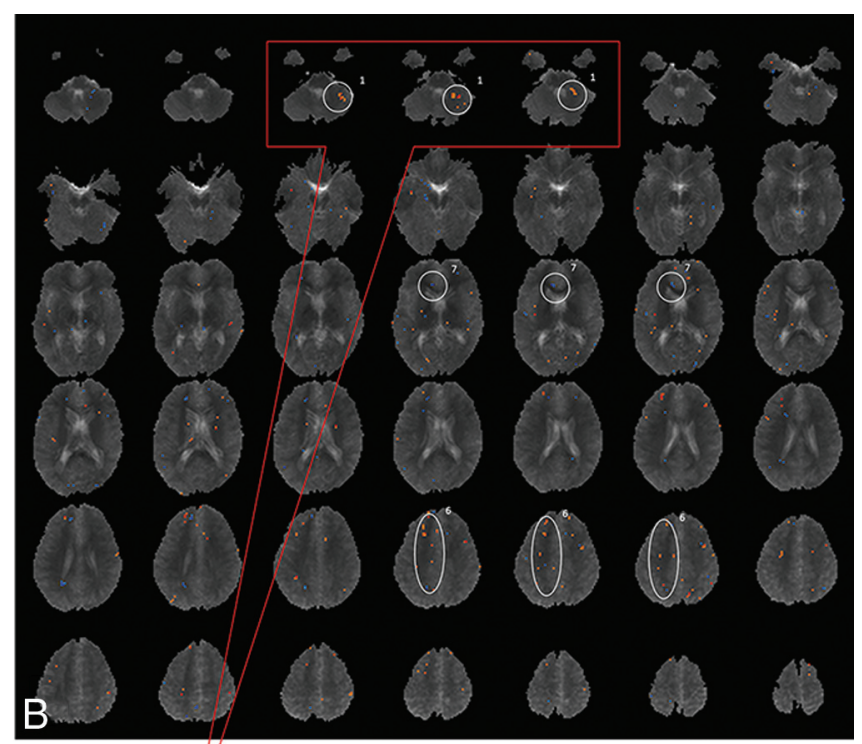

Mean Diffusivity (MD) Mapping

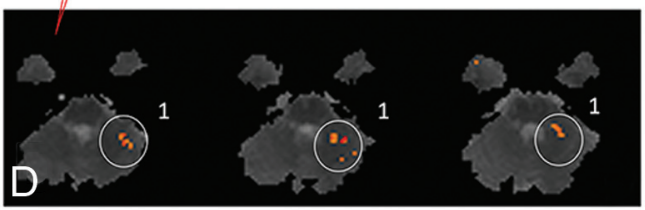

FIG 1. Voxel-based analysis comparing the brains of children born from preeclamptic pregnancies with the brains of children born from typical healthy pregnancies (controls). A custom template was created on the basis of the anatomic images of all 20 children enrolled in this study. Voxel-based analysis was performed to compare white matter measurements in PE-Fls and control children. The blue and red dots represent areas where there might have been differences between the fractional anisotropy values $(A$ and $C)$ or mean diffusivity values $(B$ and $D)$. From the voxel-based analysis, areas in which a cluster of voxels persisted through at least $\geq 3$ sections were identified and used to define the specific ROIs to be used as seeds for tractography. Magnification of an area ( $C$ and $D)$ is used as an example of how ROls were defined. The 3 most dot-clustered regions in voxel-based analysis for FA and MD were selected, yielding 6 ROIs for more detailed analysis. The ROIs identified on FA were the following: 2, middle occipital gyrus; 7, caudate nucleus; and 9, precuneus. The ROls identified on MD were the following: 1, cerebellum; 6, superior longitudinal fasciculus; and 7, cingulate gyrus.

too many tracts of interest. Therefore, voxel-based analyses in the second step were evaluated at a significance level of $P \leq .01$ to narrow down the search to white matter regions of possible interest. In the third step, tractography was performed at the $P \leq .05$ level as a standard value, because these data represent the first study of this kind on this defined group of individuals of any age and there were no previously published analyses for guidance.

\section{RESULTS}

\section{Voxel-Based Analysis}

Voxel-based analysis of differences between PE-F1s and typical children statistically identified 10 regions of difference in FA and 8 regions of difference in MD. The final ROIs selected for tractography analysis were the 3 most different on the basis of voxelbased analysis of FA (middle occipital gyrus, caudate nucleus, and precuneus) and the 3 most different identified by voxel-based analysis of MD (cerebellum, superior longitudinal fasciculus, and cingulate gyrus; Fig 1).

\section{Tractography in ROIs}

From the 6 identified ROIs, 3 differed between PE-F1s and control children. The regions for which statistical differences in any tractography parameter could not be established with this small study group were the middle occipital gyrus $(P=.26-0.47)$, pre- cuneus $(P=.12-0.48)$, and cerebellum $(P=.47-0.77)$. The regions showing differences were the caudate nucleus, superior longitudinal fasciculus, and cingulate gyrus. Multivariate statistical analysis revealed differences for FA in the caudate nucleus (PEF1 $>$ control, $P=.008$ ), tract volumes for the caudate nucleus (PE-F1 $>$ control, $P=.05$ ) and the superior longitudinal fasciculus (PE-F1 $>$ control, $P=.03$ ), and parallel diffusion for the cingulate gyrus ( $\mathrm{PE}-\mathrm{F} 1>$ control, $P=.04$ ). Complete comparisons of the DTI parameters between the PE-F1 and typical children are summarized in the On-line Table.

\section{Integration with MR Imaging/MRA Outcomes}

The Table summarizes the overlap in findings between the DTI analyses and our previous analyses of brain images from these PE-F1s. ${ }^{14}$ The independent DTI analyses identified differences in brain areas between the groups that corresponded with results from our previous analyses. For example, the larger brain anatomic areas described previously in PE-F1 (temporal lobe, right and left amygdalae) were coincident with a higher volume of bundles of white matter (superior longitudinal fasciculus and caudate nucleus) and also with higher values of FA (caudate nucleus). Most important, the right and left amygdalae are part of the limbic area, and they are localized at the end point of the caudate nucleus. Although larger tissue volumes were described in the cere- 


\begin{tabular}{|c|c|c|c|c|}
\hline \multirow[b]{2}{*}{$\begin{array}{l}\text { Brain Anatomic } \\
\text { Regions }\end{array}$} & \multicolumn{2}{|c|}{ DTI Findings in PE-F1 Brains (Present Study) } & \multicolumn{2}{|c|}{ MRI/MRA, Previous Findings in PE-F1 Brains ${ }^{14}$} \\
\hline & ROIs & $\begin{array}{l}\text { Comparisons with Significant } \\
\text { Differences between } \\
\text { PE-Fls and Controls }\end{array}$ & $\begin{array}{l}\text { Morphologic Findings } \\
\text { in PE-F1 }\end{array}$ & $\begin{array}{l}\text { Vascular Findings } \\
\text { in PE-F1 }\end{array}$ \\
\hline Temporal lobe & $\begin{array}{l}\text { Superior longitudinal } \\
\text { fasciculus }\end{array}$ & $\begin{array}{l}\text { Volume of tract: PE-Fls }> \\
\quad \text { controls }(P=.03)\end{array}$ & $\begin{array}{l}\text { Larger volume in temporal } \\
\text { lobe }\end{array}$ & NS \\
\hline \multirow[t]{2}{*}{ Limbic area } & Caudate nucleus & $\begin{array}{l}\text { FA: } \text { PE-Fls }>\text { controls }(P=.008) \\
\quad \text { volume of tract: } P E-F l s> \\
\quad \text { controls }(P=.05)\end{array}$ & $\begin{array}{l}\text { Larger volume in right and } \\
\text { left amygdalae }\end{array}$ & NS \\
\hline & Cingulate gyrus & $\begin{array}{l}\text { Parallel diffusion: } \mathrm{PE}-\mathrm{Fls}> \\
\quad \text { controls }(P=.0 .04)\end{array}$ & NS & NS \\
\hline Parietal lobe & Precuneus & NS & NS & Smaller radii globally \\
\hline Occipital lobe & Middle occipital gyrus & NS & NS & Smaller radii globally \\
\hline Cerebellum & Cerebellum & NS & Larger volume in cerebellum & NS \\
\hline
\end{tabular}

Note:-NS indicates that no significant correlation or comparison was found.

bellum, and smaller vascular radii in the parietal and occipital lobes, we did not find any significant deviations in these regions in the advanced DTI analysis. However, the voxel-based analysis of FA and MD parametric maps did identify regions that are part of or correspond to the cerebellum, parietal lobe, and occipital lobe.

\section{DISCUSSION}

This is the first report of DTI analyses of the PE-F1 brain. In this small pilot study, unbiased comparisons identified some brain areas with significant differences in DTI parameters between PEF1s and children matched except for gestationally experienced maternal health status.

The origins of the impacts of PE defined in our study are unclear. Possibilities include effects that are direct consequences of maternal hypertension or that result from disturbed placental metabolism or function. However, we postulate that the effects arise from angiogenic dysregulation in the fetus itself that mirrors the angiogenic dysregulation displayed in the conceptus-derived placenta and are reflected in measurements of maternal gestational plasma. Thus, we predict that the legacy effects of the preeclamptic gestational experience are not restricted in brains of PE-F1 but are present in multiple vascular beds. This postulate was recently supported by studies of capillaries in early postnatal infant skin. ${ }^{20}$

The PE-F1 deviations of increased brain regional volumes or globally reduced vascular diameters suggest that the legacy impact of PE occurred in regions associated with memory and visual spatial processing. ${ }^{14,16}$ Our previous findings that the temporal lobe and right and left amygdalae in PE-F1 are larger than in control children were coincident with the larger DTI volume of white matter in 2 ROIs: the caudate nucleus and superior longitudinal fasciculus (Table).

In our PE-F1 study participants, increased tract volumes were identified in the superior longitudinal fasciculus, which is a large bundle of association fibers in the white matter that connects the parietal, occipital, and temporal lobes with the frontal lobe. ${ }^{21}$ The superior longitudinal fasciculus is strongly related to language and communication pathways. ${ }^{21}$ Due to a small sample, we could not establish a statistical correlation between these findings; larger, future studies are needed to address possible relationships.

PE-F1s had higher FA values and thicker white matter bundles over tracts in the caudate nucleus. The limbic area, represented mainly by the caudate nucleus, has an important role in learning and memory involving goal-directed actions. ${ }^{22}$ The brain circuits that underlie spatial working memory include the prefrontal cortex, anterior cingulate cortex, basal ganglia, thalamus, and cerebellum. ${ }^{23} \mathrm{PE}-\mathrm{F} 1$ presented with higher parallel diffusion values in the cingulate gyrus (On-line Table), which corresponds to additional support for differences in the PE-F1 limbic area. DTI identification of higher FA values and a higher volume of white matter tracts on the caudate nucleus plus higher parallel diffusion on the cingulate gyrus predict an impact on spatial working memory in PE-F1 compared with control children. Again, due to the limited sample size, it is not possible to infer whether the observed changes would have a positive or negative impact on this group of children. Similarly, future assessment of a larger number of individuals will be needed to verify possible associations between the limbic area and spatial working memory.

In animal models, placental growth factor (PGF)-deficient mice (PGF mutant knockout mice) display altered fetal brain vascular development from midpregnancy. ${ }^{24}$ Key deviations identified were in vessels of the hindbrain and circle of Willis. ${ }^{25}$ PGF is expressed in all stages of mouse and human preimplantation embryos and throughout brain development. ${ }^{26,27}$ In women who proceed to PE, subnormal maternal plasma levels of PGF, predominantly a placental product, are reported by the end of first trimester when significant elevations first appear in healthy pregnancies. ${ }^{28,29}$ Consistent with this finding, PGF was deficient in the available term plasma samples of the mothers of the children studied in this report while soluble fms-like tyrosine kinase- 1 and soluble endoglin were comparable ( $n=4 \mathrm{PE} / 8$ controls). ${ }^{14}$ Our hypothesis is that in PE, downregulation of PGF and/or related angiogenic signaling molecules is initiated at or before embryo implantation. This predicts PGF downregulation in both the placenta and embryo/fetus during the interval of brain development. Indeed, in cattle blastocysts in which data are available, PGF transcripts are more than twice as numerous in the inner cell mass (fetal primordium) than in the trophectoderm, the primordium for the placenta. ${ }^{30}$

We speculate that neurologic and vascular development of the embryonic/fetal brain is already deviated before differences in PGF and/or other molecules regulating angiogenesis are detectable in maternal plasma or before maternal hypertension is clin- 
ically observed. Vascular and neurologic imaging of neonatal human and mice brains has identified early life capacities for significant structural reorganization. If validation studies with a large number of participants confirm our pilot data, development of preclinical models to assess methods of stimulating neonatal brain angiogenesis to reduce cognitive impairment may be appropriate. ${ }^{31-34}$ It will also be important to compare PE-F1 brain images and functioning with similar data associated with other types of pediatric brain developmental anomalies to understand whether the PE-F1 brain is unique and whether imaging data could be clinically valuable for long-term health management of these individuals.

\section{CONCLUSIONS}

Our continuing analyses of brain MR imaging datasets from a small number of 7 - to 10-year-old PE-F1s strongly suggest that neurologic differences underlie the intellectual deviations reported in pediatric and adult PE-F1 populations. ${ }^{5-14}$ The brain regions with statistically significant DTI differences were previously identified in an independent analysis as having anatomic variances in volume or global vessel width compared with children born from typical pregnancies. ${ }^{14}$ Our studies, though limited by a small sample size and racial homogeneity (white), strongly suggest that $\mathrm{PE}$ causes deviation of fetal brain structures during early development before the onset of maternal hypertension and that these deviations might have functional consequences postpartum.

\section{ACKNOWLEDGMENTS}

We thank Dr Brandon Maser (Queen's University) for helpful discussions and collaboration and Mr Don Brien (Queen's University) for technical support. We additionally thank all of the participants and their parents who volunteered for this study.

Disclosures: Ernesto A. Figueiró-Filho-RELATED: Grant: Coordenação de Aperfeiçoamento de Pessoal de Nível Superior, Comments: Postdoctoral Training Award-Estágio Sênior, grant No. 99999.002771/2015-02. I was granted a 1-year postdoctoral fellowship from Brazil to accomplish this research project; UNRELATED: Grants/Grants Pending: Kingston General Hospital Research Foundation, Comments: internal institutional award administered through Queen's University, Kingston, Ontario, for the Kingston General Hospital Research Foundation. The amount of the award was Can\$10,000. B. Anne Croy-RELATED: Principal Investigator on the 1-year internal institutional award administered through Queen's University, Kingston, Ontario, for the Kingston General Hospital Research Foundation made June 1, 2014. These funds covered the MRI user fees for the studies reported in the article*; Other: Garfield Kelly and Harry Botterell Foundation for the Neurological Sciences, Comments: internal competitive funds of Can\$10,000 from Queen's University for June 1, 2015, from the Garfield Kelly Award (Can\$2500) and the Botterell Foundation (Can\$7500).* *Money paid to the institution.

\section{REFERENCES}

1. American College of Obstetricians and Gynecologists; Task Force on Hypertension in Pregnancy. Hypertension in pregnancy: report of the American College of Obstetricians and Gynecologists' Task Force on Hypertension in Pregnancy. Obstet Gynecol 2013;122: 1122-31 CrossRef Medline

2. Kenny LC, Black MA, Poston L, et al. Early pregnancy prediction of preeclampsia in nulliparous women, combining clinical risk and biomarkers: the Screening for Pregnancy Endpoints (SCOPE) international cohort study. Hypertension 2014;64:644-52 CrossRef Medline

3. Lo JO, Mission JF, Caughey AB. Hypertensive disease of pregnancy and maternal mortality. Curr Opin Obstet Gynecol 2013;25:124-32 CrossRef Medline

4. Verdonk K, Saleh L, Lankhorst S, et al. Association studies suggest a key role for endothelin-1 in the pathogenesis of preeclampsia and the accompanying renin-angiotensin-aldosterone system suppression. Hypertension 2015;65:1316-23 CrossRef Medline

5. Pinheiro TV, Brunetto S, Ramos JG, et al. Hypertensive disorders during pregnancy and health outcomes in the offspring: a systematic review. J Dev Orig Health Dis 2016;7:391-407 CrossRef Medline

6. Ehrenstein V, Rothman KJ, Pedersen L, et al. Pregnancy-associated hypertensive disorders and adult cognitive function among Danish conscripts. Am J Epidemiol 2009;170:1025-31 CrossRef Medline

7. Tuovinen S, Eriksson JG, Kajantie E, et al. Maternal hypertensive disorders in pregnancy and self-reported cognitive impairment of the offspring 70 years later: the Helsinki Birth Cohort Study. Am J Obstet Gynecol 2013;208:200.e1-9 CrossRef Medline

8. van Wassenaer AG, Westera J, van Schie PE, et al. Outcome at 4.5 years of children born after expectant management of early-onset hypertensive disorders of pregnancy. Am J Obstet Gynecol 2011;204: 510.e1-9 CrossRef Medline

9. Heikura U, Hartikainen AL, Nordström T, et al. Maternal hypertensive disorders during pregnancy and mild cognitive limitations in the offspring. Paediatr Perinat Epidemiol 2013;27:188-98 CrossRef Medline

10. Morsing E, Maršál K. Pre-eclampsia- an additional risk factor for cognitive impairment at school age after intrauterine growth restriction and very preterm birth. Early Hum Dev 2014;90:99-101 CrossRef Medline

11. Whitehouse AJ, Robinson M, Newnham JP, et al. Do hypertensive diseases of pregnancy disrupt neurocognitive development in offspring? Paediatr Perinat Epidemiol 2012;26:101-08 CrossRef Medline

12. Tuovinen S, Räikkönen K, Kajantie E, et al. Hypertensive disorders in pregnancy and intellectual abilities in the offspring in young adulthood: the Helsinki Birth Cohort Study. Ann Med 2012;44:394403 CrossRef Medline

13. Tuovinen S, Räikkönen K, Kajantie E, et al. Hypertensive disorders in pregnancy and cognitive decline in the offspring up to old age. Neurology 2012;79:1578-82 CrossRef Medline

14. Rätsep MT, Paolozza A, Hickman AF, et al. Brain structural and vascular anatomy is altered in offspring of pre-eclamptic pregnancies: a pilot study. AJNR Am J Neuroradiol 2016;37:939-45 CrossRef Medline

15. Rätsep MT, Hickman AF, Croy BA. The Elsevier trophoblast research award lecture: impacts of placental growth factor and preeclampsia on brain development, behaviour, and cognition. Placenta 2016;48(suppl 1):S40-S46 CrossRef Medline

16. Rätsep MT, Hickman AF, Maser B, et al. Impact of preeclampsia on cognitive function in the offspring. Behav Brain Res 2016;302: 175-81 CrossRef Medline

17. Smith GN, Walker MC, Liu A, et al. A history of preeclampsia identifies women who have underlying cardiovascular risk factors. $\mathrm{Am} \mathrm{J}$ Obstet Gynecol 2009;200:58:e1-8 CrossRef Medline

18. Leemans A, Jeurissen B, Sijbers J, et al. ExploreDTI: a graphical toolbox for processing, analyzing, and visualizing diffusion MR data. In: Proceedings of the 17th Annual Meeting of the International Society for Magnetic Resonance in Medicine, Honolulu, Hawaii. April 18-24, 2009:3537

19. Garcia-Vazquez V, Reig S, Janssen J, et al. Use of IBASPM atlas based automatic segmentation toolbox in pathological brains: effect of template selection. In: Proccedings of the IEE Nuclear Science Symposium Conference, October 19-25, 2008. Dresden, Germany

20. Yu GZ, Aye CY, Lewandowski AJ, et al. Association of maternal antiangiogenic profile at birth with early postnatal loss of microvascular density in offspring of hypertensive pregnancies. Hypertension 2016;68:749-59 CrossRef Medline

21. Kamali A, Flanders AE, Brody J, et al. Tracing superior longitudinal fasciculus connectivity in the human brain using high resolution 
diffusion tensor tractography. Brain Struct Funct 2014;219:269-81 CrossRef Medline

22. Grahn JA, Parkinson JA, Owen AM. The role of the basal ganglia in learning and memory: neuropsychological studies. Behav Brain Res 2009;199:53-60 CrossRef Medline

23. Luna B, Velanova K, Geier CF. Development of eye-movement control. Brain Cogn 2008;68:293-308 CrossRef Medline

24. Rätsep MT, Carmeliet P, Adams MA, et al. Impact of placental growth factor deficiency on early mouse implant site angiogenesis. Placenta 2014;35:772-75 CrossRef Medline

25. Rätsep MT, Felker AM, Kay VR, et al. Uterine natural killer cells: supervisors of vasculature construction in early decidua basalis. Reproduction 2015;149:R91-102 CrossRef Medline

26. Luna RL, Kay VR, Rätsep MT, et al. Placental growth factor deficiency is associated with impaired cerebral vascular development in mice. Mol Hum Reprod 2016;22:130 - 42 CrossRef Medline

27. Miller JA, Ding SL, Sunkin SM, et al. Transcriptional landscape of the prenatal human brain. Nature 2014;508:199-206 CrossRef Medline

28. Levine RJ, Maynard SE, Qian C, et al. Circulating angiogenic factors and the risk of preeclampsia. N Engl J Med 2004;350:672-83 CrossRef Medline

29. Zeisler H, Llurba E, Chantraine F, et al. Predictive value of the sFlt1:PIGF ratio in women with suspected preeclampsia. $N$ Engl J Med 2016;374:13-22 CrossRef Medline

30. Khan DR, Fournier É, Dufort I, et al. Meta-analysis of gene expression profiles in granulosa cells during folliculogenesis. Reproduction 2016;151:R103-10 CrossRef Medline

31. Harb R, Whiteus C, Freitas C, et al. In vivo imaging of cerebral microvascular plasticity from birth to death. J Cereb Blood Flow Metab 2013;33:146-56 CrossRef Medline

32. Whiteus C, Freitas C, Grutzendler J. Perturbed neural activity disrupts cerebral angiogenesis during a postnatal critical period. $\mathrm{Na}$ ture 2014;505:407-11 CrossRef Medline

33. Panigrahy A, Borzage M, Blüml S. Basic principles and concepts underlying recent advances in magnetic resonance imaging of the developing brain. Semin Perinatol 2010;34:3-19 CrossRef Medline

34. Staudt M. Brain plasticity following early life brain injury: insights from neuroimaging. Semin Perinatol 2010;34:87-92 CrossRef Medline 